\title{
Proceeding
}

9th INSHS International Christmas Sport Scientific Conference, 4-6 December 2014. International Network of Sport and Health

Science. Szombathely, Hungary

\section{The emotional benefits of the motor activity in developmental age}

\author{
VINCENZA D'AMICO ${ }^{1}$, PAOLA DAMIANI ${ }^{2}$, FILIPPO GOMEZ PALOMA ${ }^{1}$ \\ ${ }^{1}$ Department of Human, Philosofical and Education Science, University of Salerno, Italy \\ 2 Department of Philosophical and Education Science, University of Turin, Italy
}

\begin{abstract}
D'Amico, V., Damiani, P., \& Gomez, F. (2015). The emotional benefits of the motor activity in developmental age. J. Hum. Sport Exerc., 9(Proc1), pp.S455-S461. Introduction: Scanlan and Simons (1992), define the "enjoyment" in the sport as a positive affective answer toward the sporting experience. It is important to conceive the reasons of the pleasure in the motor activities, because this would help the researchers to elaborate strategies of intervention more and more effective that keeps in mind of the individuals. The objective of the search is to understand if the motor activity is appreciate by children and if it offers benefits. The intervention on the field is developed with the CSI (Centro Sportivo Italiano) of Cava de' Tirreni (SA), that it has organized a project of motor activity, having involved children since 7 to 11 years old, among which also of the disabled persons. The search has been divided in three phases: Theoretical-practice phase, where a circle time has been organized to forming the children to the emotions, to differentiate and recognize them. Then, with a questionnaire, information are picked up respect the emotional state of departure: the children have individualized the image of the emotion that more it represented them. Practice phase, where the boys have developed motor activity (games, crossed motor). Conclusive phase, where they have been picked the impressions just tried by children respect the motor activity turn. The search is concluded administering the PACES test (Phisycal Activity Enjoyment Scale, Kendzierski \& De Carlo, 1991), tool used for the evaluation of the motor activity. The result has been that following the motor activity the positive emotions are increased tried by children, while the negative emotions result redoubts and/or repressed. Examining the obtained data, the majority of the children appreciate the motor activity, has lived himself pleasantly and offers them positive benefits. From the search an objective for the future could be characterized: to induce the children to regularly practice motor activity because in degree to arouse positive emotions and to guarantee psycho-physical comfort. Keywords: MOTOR ACTIVITY, EMOTION, ENJOYMENT, PACES, DEVELOPMENT.
\end{abstract}

\footnotetext{
Corresponding author. Department of Human, Philosofical and Education Science, University of Salerno, Italy E-mail: fgomez@unisa.it. 9th INSHS International Christmas Sport Scientific Conference, 4-6 December 2014. International Network of Sport and Health Science. Szombathely, Hungary. JOURNAL OF HUMAN SPORT \& EXERCISE ISSN 1988-5202

(c) Faculty of Education. University of Alicante doi:10.14198/jhse.2015.10.Proc1.39
} 


\section{INTRODUCTION}

This article contains the analysis of the experience carried out in the field, with the direct experimentation on emotions.

Field research is to respond to some questions: motor activity provides emotional benefits and is experienced by children pleasantly?

The regular practice of physical activity is recognized in many documents as a fundamental element for the promotion and maintenance of health, physical and psychological, in all ages of life. Despite this, the majority of individuals in industrialized countries does not reach the minimum recommended levels of physical activity (150 minutes / week for adults, 300 minutes / week for children, ACSM, 1998; Centers for Disease Control and Prevention, 2006), does not engage in physical activities and consistently adopts increasingly sedentary behaviors.

The fun and pleasure (fun and enjoyment in the Anglo-Saxon cultural tradition to which it refers most of the literature on this topic) are among the main reasons why individuals, at all ages, engage in physical activities and sports, while the lack of pleasure frequently leads to a holding occasional or abandonment (Garn \& Cothran, 2006; O'Reilly, Tompkins \& Gallant, 2001).

Motor activities, and the game motor in particular, generate the individual feelings of great pleasure and pleasantness, and especially in younger children, the movement produces rewards that have no equal in any other activity.

Reviewing literature sull'enjoyment, Scanlan and Simons define the enjoyment in sport as "a positive affective response to the sporting experience that reflects generalized feelings such as pleasure, friendliness and fun."

Scanlan and Lewthwaite emphasize four key elements in the field of pleasure in physical activities and sports:

1) It is important to understand the significance of positive emotions (mainly the pleasure and the fun) when considering individual motivation in physical activities and sports.

2) There are several elements that can make the sport and physical activity and pleasant. These may vary according to the characteristics of each individual (such as friendships, experiences, perceived ability, recognition from others, the feeling physical movement). For this it is important that in situations of movement is always made accessible wide variety of elements so as to ensure an motor pleasant to the largest possible number of people.

3) Both the intrinsic factors, as extrinsic factors of fun-oriented success can be pleasant. An individual may also find the pleasant feel competent in the performance of the task (which is equivalent to being intrinsically motivated) or see recognized his performance, in terms of approval and praise, from an external source (which is equivalent to be extrinsically motivated).

4) Factors not oriented to success in physical activities and sports, such as socializing with peers, can increase motivation, pleasure and individual fulfillment. 
In the international literature emphasizes how students and teachers confined in the pleasure of the main objectives for physical education (O'Reilly, Tompkins, Gallant, 2001; Supaporn, Griffin, 1998), the same way the pleasure seems to be a determining factor in the sport and, more generally, in the participation regular physical activity recreational, youth, adults and seniors (Frederick, Morrison \& Manning, 1996; Hashim, Grove \& Whipp, 2008; De Gracia, 2000).

Despite this, the pleasure remains a poorly considered in the research concerning the relationship between physical activity and health, where there is given only marginal attention. In Italy, in particular, the study of size related to the entertainment and pleasure in sports and physical activities remained until very recently, virtually ignored, and only in recent years has begun to include this aspect in research involving especially physical education, but also the practice of youth sports and fitness world.

To promote the practice of physical activities and to improve existing services you need to understand the reasons that lead people to engage regularly in physical activity, overcoming the typical size of the exercise prescription based on medicalization, the excessive motor activity technicalization and on mechanisms related to fear: "you need to do exercise because otherwise you get sick." Studying the determinants of decision making and the role that the fun and pleasure playing assumption and maintaining an active lifestyle is a key element in the design of actions to promote the regular practice of physical activities in individuals (Raiola, Tafuri \& Gomez Paloma, 2014).

Several authors (Deci \& Ryan, 1985; Pelletier et al., 1995) point out that there is a close connection between pleasure and intrinsic motivation, almost as if the two constructs were among them interchangeable. It is expected that pleasant experiences during physical activity enhance the intrinsic motivation, develop positive attitudes and promote the long-term adherence to the practice (Raiola, Scassillo, Parisi \& Di Tore, 2013).

Objective

This research stems from my interest in the emotional field and has as its key objective to make people think about the need to pay more attention to this world.

What I wanted to examine the field research is whether the motor activity is appreciated by children and if this gives them positive or negative benefits (Gomez Paloma, Rio \& D'Anna, 2014).

It is important to conceive the reasons of pleasure in physical activities and the relationship between pleasure and other psychological variables, because this could help researchers develop more effective intervention strategies that take into account the different characteristics and needs of individuals.

After we find the answer to these research questions.

\section{METHODS}

The surgery took place on the field during a project of motor activity organized by CSI (Italian Sports Center) of Cava de 'Tirreni (SA), addressed to pupils of primary school and secondary school degree.

The research was developed in three phases: the first phase theory and practice that was aimed to familiarize children with the emotions and to gather information about their state of origin, through a circle time and the administration of a simple questionnaire; follows the second phase so-called practice during 
which the boys have played the games; in the third phase, the children have played before the questionnaire before the motor activity and then test Phisycal Activity Enjoyment Scale (PACES).

\section{RESULTS AND DISCUSSION}

Are set out below the results obtained from the questionnaire presented to children, from which it was extracted at first a comparison of individual emotions (sad, angry, bored, happy and cheerful) try, both before and after having worked as physics; later, to give a picture on the whole, has been chosen to define more precisely the data you want to analyze distinguishing positive emotions from negative emotions experienced by children, always analyzing before and after exercise.

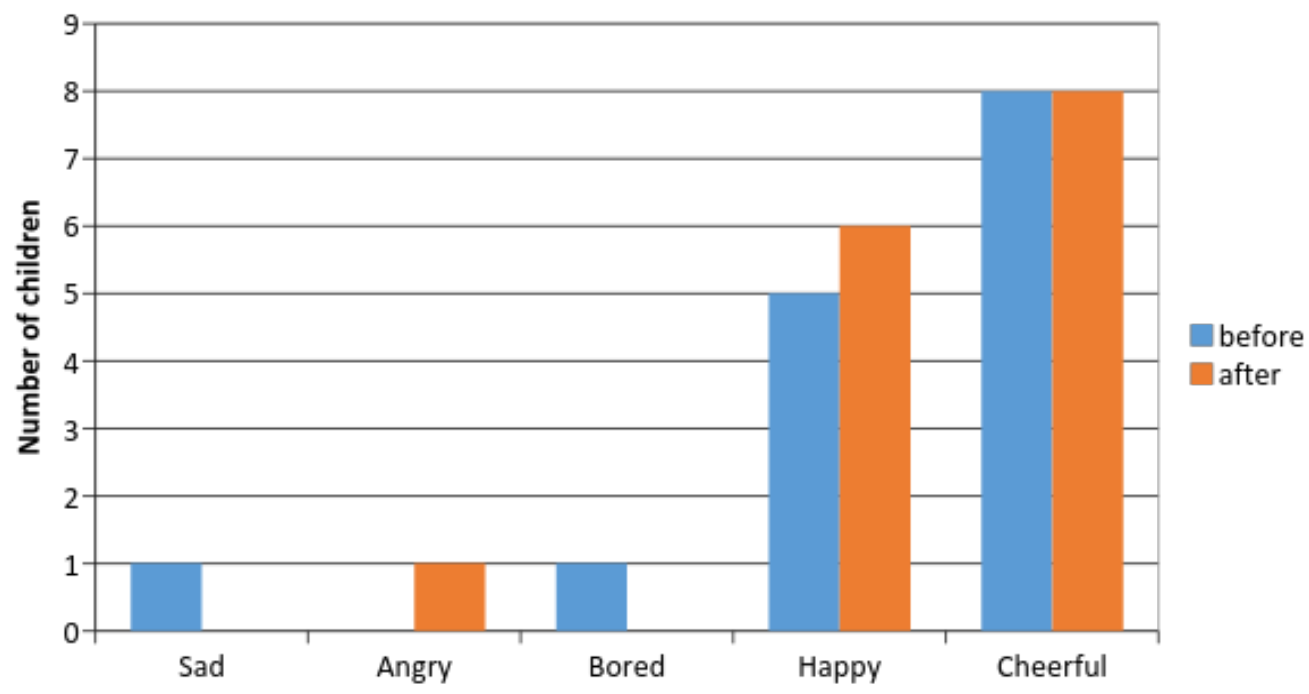

Figure 1. Chart of the emotions felt by the children before and after exercise

Looking at the results, it is evident that, by making a comparison between the "before" and "after", positive emotions experienced by children are aumentale and given even more significant, negative emotions have been reduced; Therefore, it is assumed that later motor activity, children tend to change their negative emotions into positive.

Finally I have given to children test Phisycal Activity Enjoyment Scale (PACES), one of the most used tools for assessing dell'enjoyment in motor activities and was developed by Kendzierski and De Carlo in 1991.

The test (revised and crossed into Italian by Carraro, Young \& Bonazza in 2008), is composed of 16 items "bipolar" with five response options for each statement: 1 (completely disagree) to 5 (completely agree).

The PACES consists of two subscales: there are nine items positive and 7 negative. 


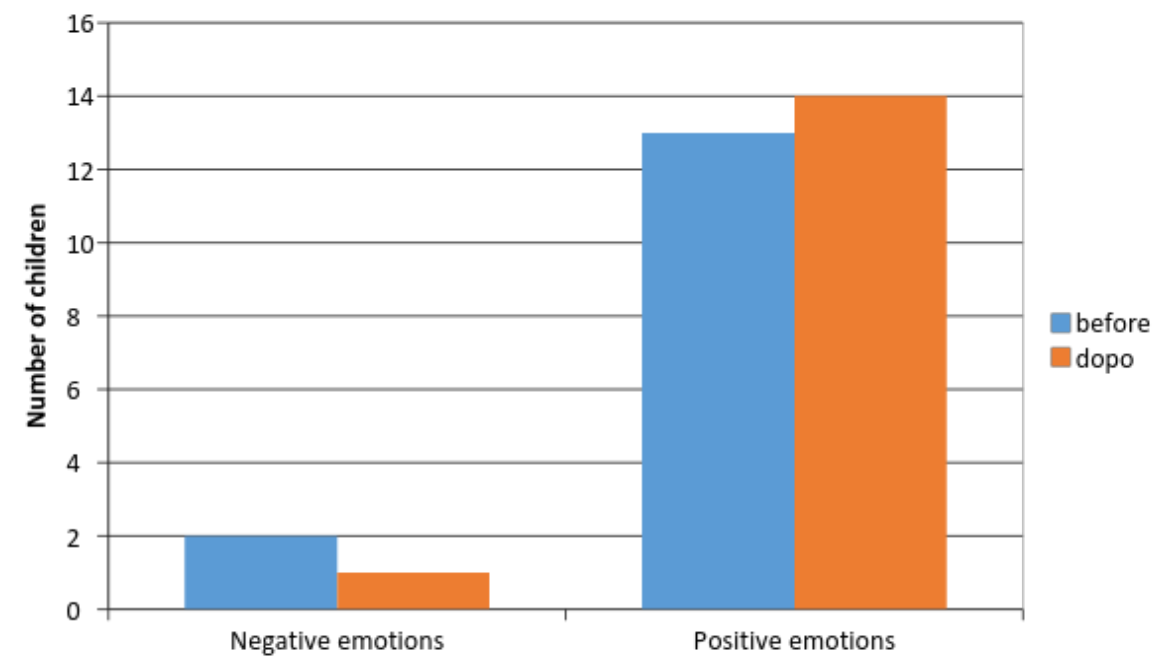

Figure 2. Chart on the difference between the negative and positive emotions felt by the children before and after physical activity

From an application point of view, the availability of an instrument for the measurement of pleasure in activities and sports can allow teachers to assess the effectiveness of their teaching strategies, particularly when these are designed to increase the active participation and motivation students.

By examining the data obtained from the questionnaire PACES it can be assumed, and ascertain that the majority of children live pleasantly experience of motor activity, in fact, the positive items were positively evaluated by most of the children, while the negative items were estimated negatively from most of them.

From the graph (Fig.3) it can be seen that physical activity has a high level is appreciated by the children. They feel pleasure and they get more positives than negatives. So the hypothesis formulated in principle, namely that physical activity provides benefits to children, finds its confirmation (Gomez Paloma, Agrillo \& D'Anna, 2013).

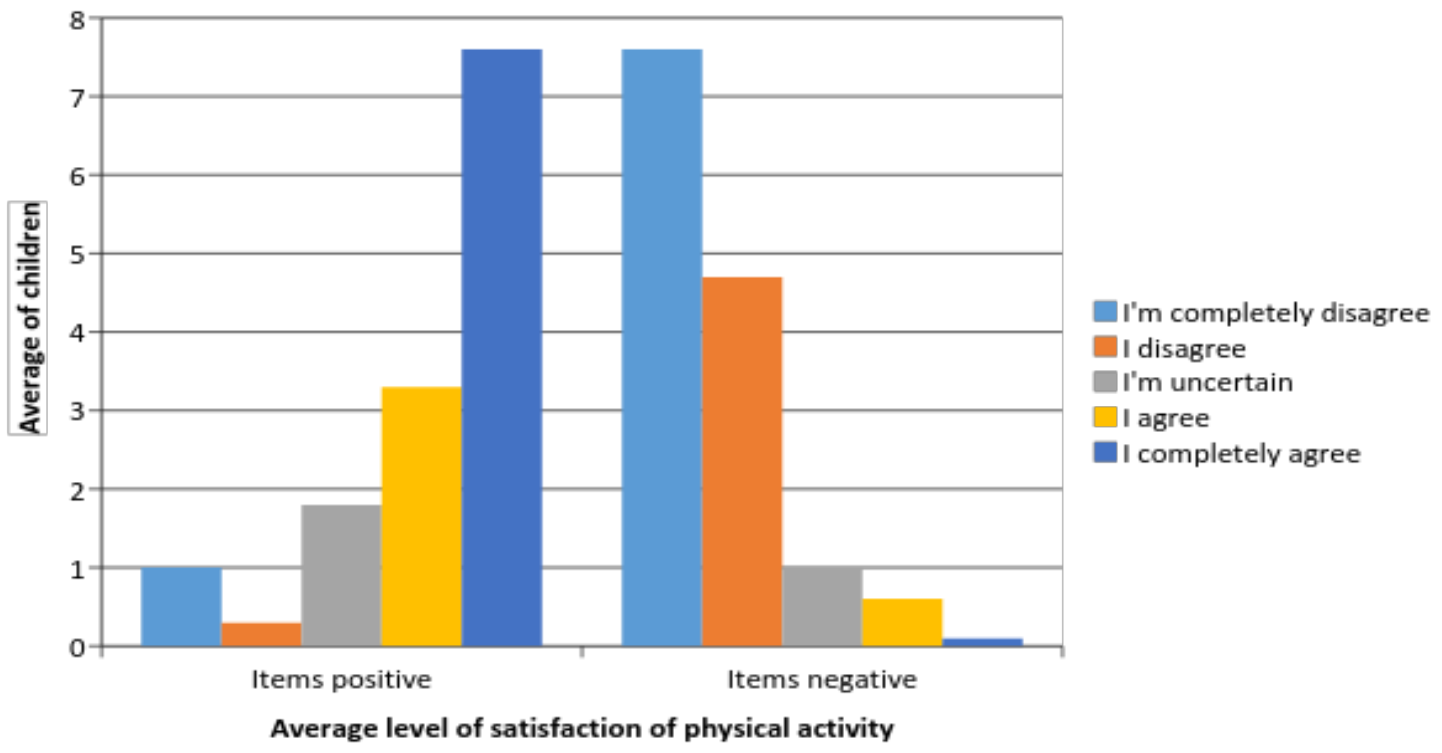

Figure 3. Chart on the level of fun and enjoyment in physical activity 
In this respect the results, you can respond to research questions and concluded that physical activity is appreciated by children and this gives them positive benefits.

In fact occurred that positive emotions are experienced much more intensely studied that negative emotions considered. The comparison between the average of all the positive emotions and all the negative emotions clearly shows this difference.

It been established that physical activity leads to a mutation of the emotions, in fact, be negative which were before the activities, become positive. This underlines, therefore, the importance of the benefits that physical activity gives the child.

\section{CONCLUSIONS}

The realization of this research has allowed us to further develop my awareness of the emotional experience of children in the practice of physical activities (Altavilla, Tafuri \& Raiola, 2014).

Consider the emotions that is more important if you want to contribute to the development of students as a whole.

One long-term goal would be to develop this work on emotions with the boys, so that they know how to recognize the emotions and then eventually get to manage them more effectively and appropriately.

Another goal, and perhaps even more difficult to achieve, would be to make them understand that the practice of any physical activity elicits predominantly positive emotions. This realization would give them the desire to practice regular physical activity over the course of their lives. Such a result may well certainly be a part of the solution to the growing problem of physical inactivity in our society.

\section{REFERENCES}

1. Altavilla, G., Tafuri, D., \& Raiola, G. (2014). Some aspects on teaching and learning by physical activity. Sport Science, 7(1), pp.7-9.

2. Dishes, L., \& Terzi, A. (2008). Emotions in play (cards to educate the emotional skills). Molfetta: La Meridiana.

3. D'Urso, V., \& Trentin, R. (1990). Psychology of emotions. Bologna: Il Mulino.

4. D'Urso, V., \& Trentin, R. (2007). Introduction to the psychology of emotions. Rome-Bari: Laterza.

5. Filliozat, I. (2001). The emotions of children. Casale Monferrato: Piemme Bestseller.

6. Frijda, N.H. (1990). Emotions. Bologna: II Mulino.

7. Gomez Paloma, F., Agrillo, F., \& D’Anna, C. (2013). Parent's perception about motor-sport activity in Italian primary school. Journal of human sport and exercise, 8(2), pp.165-179.

8. Gomez Paloma, F., Rio, L., \& D'Anna, C. (2014). Physical self-efficacy in women's artistic gymnastic between recreational and competitive level. Journal of human sport and exercise, 9(1), pp.341-347.

9. Raiola, G., Scassillo, I., Parisi, F., \& Di Tore, P.A. (2013) Motor imagery as a tool to enhance the didactics in physical education and artistic gymnastic. Journal of Human Sport and Exercise, 8(2), pp.93-97.

10. Raiola, G., Tafuri, D., \& Gomez Paloma, F. (2014). Physical activity and sport skills and its relation to mind theory on motor control. Sport Science, 7(1), pp.52-56. 
11. Scanlan T.K., Simons J.P. (1992). The construct of enjoyment. In G. C. Robert, Motivation in sport and exercise Champaign. IL: Human Kinetics.

12. Scanlan, T.K., \& Lewthwaite, R. (1986). Social psychological aspects of competition for male youth sport participants: IV. Predictors of enjoyment. Journal of Sport Psychology, 8(1), pp.25-35.

13. Steiner, C., \& Perry P. (1999). The alphabet of emotions (like conquer emotional competence). Milan: Sperling \& Kupfer.

14. Sunderland, M. (2007). Helping children to express emotions. Gardolo: Erickson. 